\title{
Energy audit of industrial enterprises on the basis of energy and resource saving evaluation
}

\author{
Valeriya Y. Anisimova ${ }^{1, *}$, Nikolay M. Tukavkin ${ }^{1}$, Ekaterina K. Chirkunova ${ }^{1}$ \\ ${ }^{1}$ Samara University, Akademika Pavlova, str. 1, Samara, 443001, Russia
}

\begin{abstract}
Modeling of an audit of industrial enterprises energy efficiency on the basis of energy and resource saving evaluation deals with the development of conceptual model domain of manufacturing enterprises resource saving and energy efficiency evaluation, and also with the clarification of the basic definitions of energy management informatization. The organizational, technical and technological development of industrial subset of analyzed enterprises is projected with regard to the continuity, cyclicality, route of all technological processes. These processes are formed by using modular-technological and readily replaceable equipment and modern informatization systems which allow to get the necessary production and managing information just-in-time for all executive staff and engineers about the run-out production and the state of production on the basis of quick and strategic synchronization of all the components of production functioning, including energetic resource saving of production processes. In order to find solutions to the named above accurate theoretical problems of audit modeling of energy and resource saving index of the industrial enterprises which are focused on the rise of energy efficiency, the complex model of evaluation of the management, production organization and resources optimization quality level is suggested, where we take as a basis theoretical and methodological principles of modeling of main components of enterprise business processes on the base of diagnostics and synchronization of production processes that are gained due to informatization systems.
\end{abstract}

\section{Introduction}

Nowadays the problems of energy efficiency are counted to be the most vital as they influence the effectiveness of the production development and the economy as a whole.

The world energy efficiency management practice is introduced in the collective works of I.V. Burenina, A.A. Batalova, D.A. Galimova, who conducted analysis of the energy efficiency programs of Russia, the USA, West Europe, Japan, China, Kazakhstan, Iran and India. They also point out the necessity of energy efficiency usage as the core principle of sustainable development of economical system [1].

O.D. Samarin, E.A. Grishneva and other authors suggest ways of buildings energy efficiency raise by using modern intellectual technologies [2-4]. The role energy and resource saving technologies in the innovative development of Russia is mentioned in the works of A.I. Shinkevich and S.S. Berman [5-7].

*Corresponding author: ipanisimova@yandex.ru 
The problem of energy efficiency of territory development projects and building activity is illustrated in the works of N.V. Gorodnova, E.K. Chirkunova [8-9]. The questions of modeling of evaluation processes of enterprises resource saving effectiveness of the industrial complex are widely illustrated in the system theory and the theory of operations research in the work of S.V. Pozhidaeva [10].

The aim of this research was to form an audit model of energy efficiency on the basis of energy and resources saving evaluation of industrial enterprises using consolidated index and taking into account industry characteristics of functioning.

\section{Methods}

The fundamental principles of economics, the scientific papers of Russian and foreign scientists in the sphere of industrial economics, the results of different applied researches how to use resource-saving and energy-efficient technologies in the industrial complex were the methodological base of the research.

Currently certain methods and approach to the evaluation of energy efficiency of industrial enterprises and buildings are formed in modern economics. However none of them can be counted as universally applicable to study this process.

As a methodological basis the following methods were used during this research: dialectic, systemic-functional, economic-statistical, economic-mathematical and technicallogical methods, and also processes modeling.

\section{Results}

An audit model of energy efficiency on the basis of energy and recourse saving evaluation of industrial enterprises is formed in a way of a dynamical connotational (objective meaning) model which describes and shows the specific character of enterprise business processes. Originally it sets the demanded level of starting data detalization, and also provides with the demanded level of control of the passing results received, the records of industrial functioning peculiarities, organization of the necessary correction and improvement of calculations when simulation modeling is realized [11].

Economical diagnostics includes not only the analysis and evaluation of condition and final results of enterprise work in order to outline «the bottleneck and weak space», but also the development of actions to raise the resource saving efficiency, including the energy and resource saving of the main functioning direction [12].

In order to model an audit of energy and resource saving the enterprise economic activity concerning tasks and objectives of economical diagnostics can be shown as a diagram. It describes the circulation of manufacturing resources, including also the energy resources by their transformation at the timeline (picture 1).

Conceptually the manufacturing process is shown by the diagram of the current assets expenditure (resources) ( $\mathrm{CF}-$ ) followed by the revenue $(\mathrm{CF}+)$, where the difference between them is the financial result from the main industrial activity. 


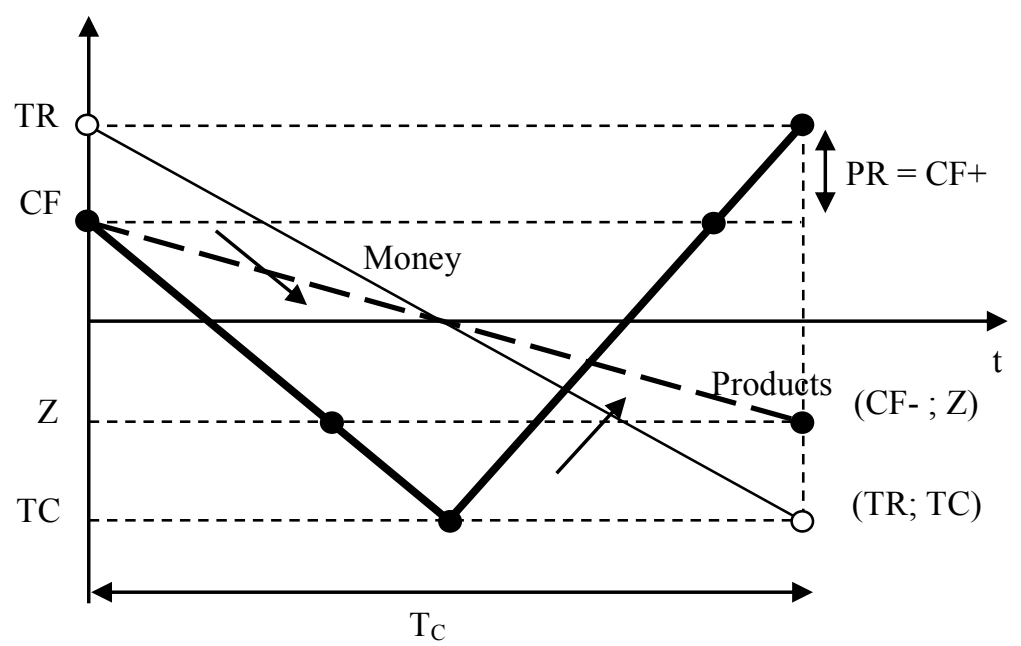

Fig. 1. Circulating cycle of enterprise resources.

The shown above interrelation of manufacturing process measures has a stable character, i.e. a dynamical system principle which allows developing a standardized system for defining the figures of enterprise resource saving efficiency. The main figures of the effect and efficiency of enterprise resource saving are:

-enterprise revenue (TR) or resulting quality of work, revenue (PR), which characterize the aiming effect (the result) the enterprise is working at;

-amount of possessed resources that are necessary for planned target or result achievement $(\mathrm{Z}=(\mathrm{K}+\mathrm{L}+\mathrm{M}+\mathrm{E}))$ or resource intensity $(\mathrm{R})$, which shows the amount of resources of all types of labor costs (L), capital input, including financial costs (K) and manufacturing (current) information (M), energy resources (E);

-asset turnover ratio or resources turnover (operability)-O, which are the figures of functioning intensity that are necessary for result achievement of the organization work;

-figures of commercial viability of enterprise functioning, i.e. the attitude of the achieved work result towards the resources expense for this result achievement $(\mathrm{P})$.

When binding these figures in time and space we get the resource saving efficiency:

$$
\mathrm{E}=\{\mathrm{PR}, \mathrm{Z}, \mathrm{O}, \mathrm{P}\}
$$

It is defined by the dynamics of its functioning, it characterizes the manufacturing capacities of the enterprise for achieving its goals and it is characterized by certain features: the quality of managing and manufacturing systems.

The general economical resource saving efficiency or manufacturing effectiveness, which is characterized by viability of enterprise resources usage, is defined by the attitude of the manufactured products value (Q) towards the whole amount of production expenses (TC) or the cost of the active resources $(\mathrm{Z})$ :

$$
\mathrm{Es}=\mathrm{Q} / \mathrm{TC} \geq 0 \text { or } \mathrm{Es} \cong \mathrm{Q} / \mathrm{Z} \geq 0 .
$$

The velocity of the industrial resources rises due to shortening the cycle time of production manufacturing, the control of its realization and making managing decisions concerning optimization of enterprise functioning resource saving on time. By doing this the amount of necessary resources can be reduced and economical efficiency of the enterprise functioning can be increased, as well as the innovations cost recovery. 


\section{Discussion}

The existence of evaluation model, which comes up to a certain financial-economical state of an enterprise, allows starting the technology of manufacturing processes synchronization that can be performed by technical audit.

In the model of energy efficiency audit the operational control of the manufacturing process should be performed not on the basis of manufacturing plans and tasks, but on the basis of informational flow evaluation, where the inputs are the real purchase ordering and demanded amount of energy, current machine load and its technical condition, the time of raw material and other physical resources input, engineering and manufacturing efficiency, and also the influence of many other factors that are taken into account in the model automatically on a rolling basis (picture 2).

The concerted activity of separate departments (or the synchronization is reached by) at the cost of application of program-methodical complex PMC "1C:Mechanical engineering 8" informatization system class ERP (Enterprise Resource Planning), which includes the main directions of manufacturing activity and the realization of enterprises products. Since the certain manufacturing departments function with different intensity, the system provides for the devices of interoperable control and management of manufacturing resources amount agreement - adapters of manufacturing rapidity [13].

This approach essentially allows to reduce the amounts of consumed energy, stock of raw materials and technological time-faults of production. However, it allows to increase the quality of products, regularity of the pace, safety and productivity of work of the enterprise on the whole.

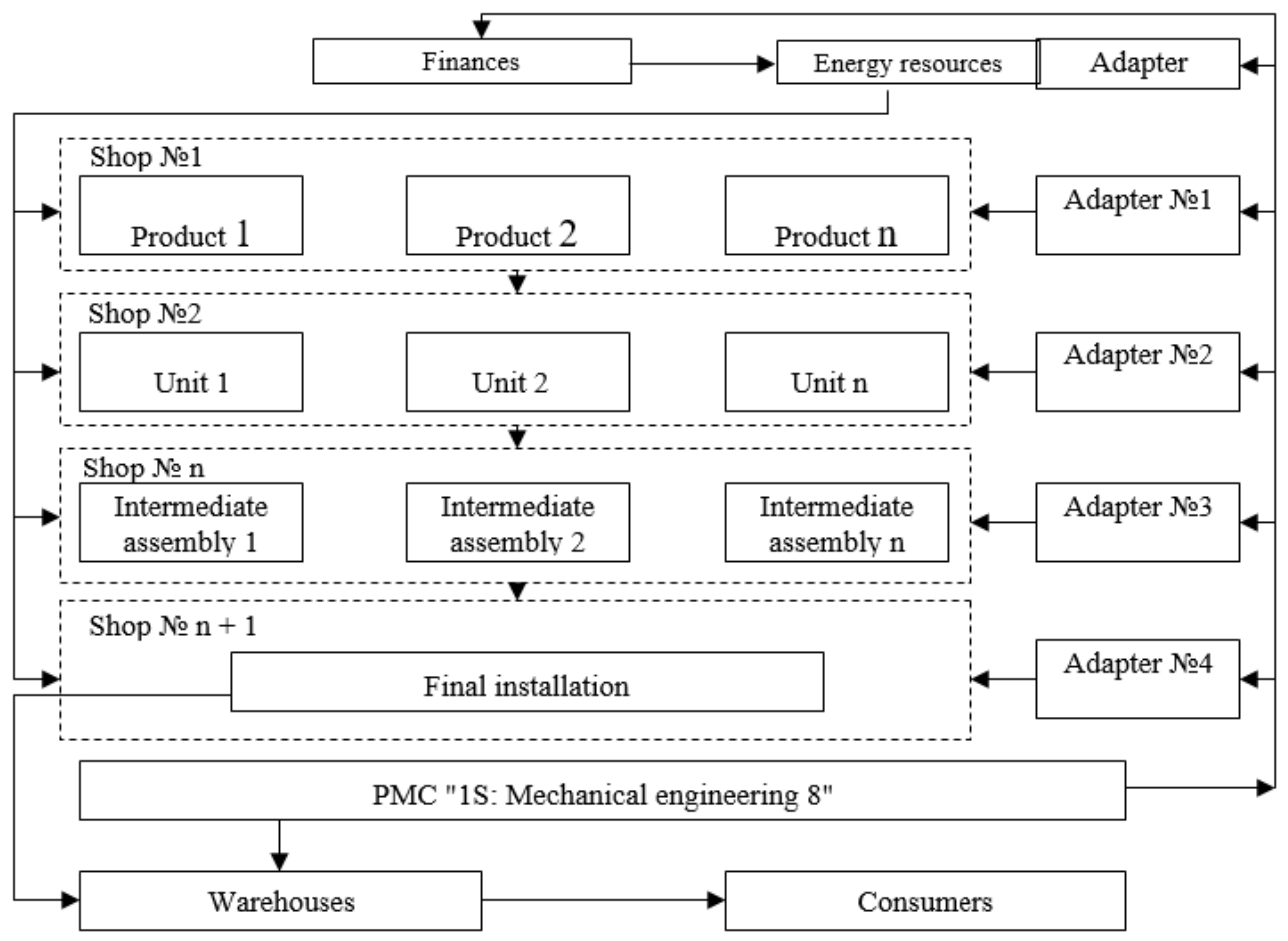

Fig. 2. Technological solution of energy efficiency audit modeling.

Conclusion: an audit model of energy efficiency on the basis of manufacturing enterprises energy and resource saving evaluation allows to analyse and estimate the 
management of manufacturing activity without using informational systems and when there are any. The decision to use the modeling helps to achieve the targets of the enterprise much faster and more effectively with the informatisation system, i.e. better quality, and business gets better economic results with the help of informational management rather than without it.

The ultimate purpose of modeling is the creation at the enterprise of an optimal structure of business-processes audit of energy and resource saving efficiency optimisation, which synchronizes the enerprise management system, the manufacturing process, energy suply, movement of materials, products and freights, and also piece of information which is based on the modern information computation system [14].

\section{Conclusions}

On the basis of the carried out research the following conclusions can be made:

1. The synergetic effect of using organizational (managing) and technical innovations by integration at the enterprise informational systems of resource saving efficiency evaluation is defined by earning gain of manufacturing and business process (profit margin) on the whole by manyfold increase of proceeds from enterprise products realization and decrease of any kinds of manufacturing expenses and resources.

2. In case of integration of resource saving efficiency informational evaluation system we get an additional effect by using organizational technological innovations which can be counted as a part of products realization profit which is gained by decrease of manufacturing operating time. It leads to the increase of velocity of manufacturing resources turnover, the increase of products quality and decrease of products prime cost. It allows getting additional product bidding and greatly increases the amounts of its realization for account of rivals that are more vulnerable concerning organisation and management. The existence of evaluation model, which corresponds to a certain financial economical state of an enterprise, allows proceeding to the technology of synchronization of manufacturing processes concerning the energy and resource saving problems.

\section{Acknowledgment}

This paper is an output of the science project No. 18-410-630001\18 "Development of mechanisms for financial provision of strategic development of the industrial complex of the Samara Region" of the Russian Foundation for Basic Research.

\section{References}

1. I.V. Burenina, A.A. Batalova, D.A. Galimova, Naukovedenie 3, 1-15 (2014)

2. O.D. Samarin, E.A. Grishneva, Energy saving and water treatment 5, 12-14 (2011)

3. D.V. Zelenin, E.L. Loginov, Economic sciences 9(70), 22-25 (2010)

4. L.V. Massel, A.G. Massel, Bulletin of the Tomsk Polytechnic University 5, 135-140 (2012)

5. M.U. Mishina, O.N. Polyakova, The Bryansk State University Herald 3(2), 62-64 (2012)

6. A.I. Shinkevich, S.S. Berman, Bulletin of the Technological University 1, 193-199 (2011)

7. N.V. Medyanik, Problems of modern Economics 1, 370-373 (2010) 
8. N.V. Gorodnova, Economic analysis: theory and practice 5(404), 31-34 (2015)

9. E.K. Chirkunova, Economic aspects of building complex management under modern conditions: int. scientific practical conf. Samara SUACE (2014)

10. S.V. Pogidaeva, Management of economic systems 3(27) (2011)

11. N.A. Kulagina, I.V. Kulagin, The economic essence of integration and evaluation of efficiency of integrated structures, 36-52 (2007)

12. D.N. Sabirova, Scientific papers of the Center for advanced economic research Academy of Sciences of RT 5, 169-174 (2012)

13. I.N. Tyukavkin, Audit and financial analysis 1, 332-336 (2017)

14. V.K. Lozenko, D.V. Mikheev, Saarbrücken (LAP LAMBERT Academic Publishing, 2016) 